\title{
Infâncias e a escola rural: traçados e bordados ${ }^{1}$
}

\section{Children and the rural school: traced and embroidered}

\author{
Josemir Almeida BARROS 2 \\ Juracy Machado PACIFICO ${ }^{3}$
}

\begin{abstract}
Resumo
Na presente pesquisa objetivamos analisar processos de instrução pública rural para crianças no início do século XX em Minas Gerais e suas representações. As fontes são documentos históricos, tais como relatórios de inspeção, legislação, Mensagens de Presidentes, dados estatísticos demográficos e escolares. Compreende-se a partir da Sociologia da Infância uma institucionalização de processos de instrução rural em que a proposta de educaçáo estava vinculada à ideia de disciplinar os sujeitos, seja pelo trabalho, seja para o trabalho. Segundo Sarmento (2008) a sociologia da infância contribui para a reflexividade contemporânea nas realidades sociais em que as crianças estão imersas.
\end{abstract}

Palavras-chave: Ensino Rural. Instrução Primária. Crianças. História da Educação.
Abstract

In this study we aim at analyzing the processes of rural public education for children in the early 20th century in Minas Gerais as well as their representations. The sources are historical documents, such as inspection reports, legislation, Presidents Messages, demographic and school statistics. It is understood from the sociology of childhood the institutionalization of rural education processes in which the proposal of education was linked to the idea of disciplining the subjects, either by work either for work. According to Sarmento (2008) the study of childhood sociology contributes to contemporary reflexivity in the social realities in which children are immersed.

Keywords: Rural Education. Primary Education. Children. History of Education.

1 A pesquisa contou com apoio financeiro do CNPq.

2 Doutor e Mestre em Educação. Pedagogo e Historiador. Professor, pesquisador e extensionista da Universidade Federal de Rondônia (UNIR) - Departamento de Ciências da Educação - (DECED) Campus Porto Velho. End.: BR 364, Km 9,5 - Setor Rural - Campus José Ribeiro Filho - Porto Velho/ RO. CEP: 76803-682. Tel. (69) 2181-2142. Email: <josemirbh@gmail.com>.

3 Doutora em Educação, Mestra em Psicologia Escolar e do Desenvolvimento Humano. Pedagoga. Professora, pesquisadora e extensionista da Universidade Federal de Rondônia (UNIR) - Departamento de Ciências da Educação - (DECED) - Campus Porto Velho. End.: BR 364, Km 9,5 - Setor Rural - Campus José Ribeiro Filho - Porto Velho/RO. CEP: 76803-682 Tel. (69) 2181-2142. Email: <juracypacifico@unir.com>.

R. Educ. Públ.

$$
\text { Cuiabá }
$$

v. 27

n. $65 / 1$ p. $385-404$ maio/ago. 2018 


\section{Conceitos e pluralidades: os traçados das infâncias e suas interfaces...}

No presente texto nos distanciamos de uma proposição de infância e/ou criança na condiçáo de homúnculos, seres humanos em miniatura e repletos de incompletudes ou imperfeiçóes. Para isso, tomamos emprestado o conceito utilizado por Kuhlmann Júnior e Fernandes: (2004, p. 15, grifos dos autores): “[...] podemos compreender a infância como a concepção ou a representação que os adultos fazem sobre o período inicial da vida, ou como o próprio período vivido pela criança, o sujeito real que vive essa fase da vida." A infância como categoria social tornou-se objeto do pensamento sociológico a partir do último quartel do século XX, e isso nos indica a emergência dessa temática; porém, ainda nos anos 30 do mesmo século, Qvortrup (1995) apontava para uma Sociologia da Infância.

Ao incorporar na sua agenda teórica a interpretação das condiçôes atuais de vida das crianças, a Sociologia da Infância insere-se decisivamente na construção da reflexividade contemporânea sobre a realidade social. (SARMENTO, 2008, p. 19).

É perceptível que diversos estudos, a exemplo dos já mencionados, buscam definir o conceito desse campo de pesquisa, que é a infância. O que entendemos por infância hoje difere de outros tempos, pois lembramos que existem contextos históricos diversos.

As crianças, não sendo consideradas como seres sociais plenos, são percepcionadas como estando em vias de ser, por efeito da ação adulta sobre as novas geraçóes. O conceito de socialização constitui, mais do que um construto interpretativo da condição social da infância, o próprio fator da sua ocultação: se as crianças são o 'ainda náo', o 'em vias de ser', não adquirem um estatuto ontológico social pleno - no sentido em que não são 'verdadeiros' entes sociais completamente reconhecíveis em todas as suas características, interativos, racionais, dotados de vontade e com capacidade de opção entre valores distintos - nem se constituem, como um objeto epistemologicamente válido, na medida em que são sempre a expressão de uma relação de transição, incompletude e dependência. (SARMENTO, 2008 , p. 20, grifos do autor). 
De acordo com o excerto acima, é possível verificarmos que estudos sobre o campo da infância que se apoiam na perspectiva de uma socializaçáo durkheimiana aderem à incompletude e à dependência. Em conformidade com a sociologia que aborda, por um lado, tal objeto de estudo (crianças) como atores sociais e a infância como categoria social geracional socialmente construída é que enfatizamos a necessidade de repensarmos tais conceitos pautados no princípio da reprodução passiva.

Apesar de todas as contribuiçóes, tanto em aspectos conceituais da infância quanto metodológicos no tratamento das fontes vindas dos trabalhos desenvolvidos por Philippe Ariès (2006), consideramos que é preciso relativizar suas proposiçôes universalizantes. Contrariando uma análise evolucionista dos processos históricos, a nova história apresenta-se como ruptura com o positivismo e, em certa medida, também com a vertente marxista.

Há quarenta anos, uma primeira crítica do 'cientificismo' desvendou na história 'objetiva' a sua relação com o lugar, o do sujeito. Analisando uma 'dissolução do objeto' (R. Aron), tirou da história o privilégio do qual se vangloriava, quando pretendia reconstituir a 'verdade' daquilo que havia acontecido. A história 'objetiva', aliás, perpetuava com essa ideia de uma 'verdade' um modelo tirado da filosofia de ontem ou da teologia de ante-ontem; contentava-se com traduzi-la em termos de 'fatos' históricos... Os bons tempos desse positivismo estão definitivamente acabados. (CERTEAU, 2006, p. 67, grifos do autor).

Duas correntes atravessaram a historiografia recente: a primeira delas é o marxismo, em que o conceito dos modos de produção é fundante; já a outra é conhecida como história nova e se apresenta contrária à história predominantemente empírica e positivista, trazendo uma forte tendência na renovação dos métodos históricos. Sobre a história nova convém destacar que:

Nascida nos anos 30, sustentada pelo prestígio de Lucien Febvre e de Marc Bloch, ela travou durante muito tempo um combate corajoso contra o positivismo que impregnava o conjunto da ideologia histórica e adquiriu, assim, uma legitima reputação pioneira. (BOIS, 1995, p. 243).

É na perspectiva de renovação metodológica e também temática que a história da infância/criança ganha destaques, e entender tal geração a partir de suas particularidades é relevar novas abordagens. 
Deste modo, não são apenas os adultos que intervêm junto das crianças, mas as crianças também intervêm junto dos adultos. As crianças não recebem apenas uma cultura constituída que lhes atribui um lugar e papéis sociais, mas operam transformaçóes nessa cultura, seja sob a forma como a interpretam e integram, seja nos efeitos que nela produzem, a partir das suas próprias práticas (a arte contemporânea, por exemplo, ilustra bem os efeitos das expressôes infantis integradas no imaginário coletivo). (SARMENTO, 2008, p. 29).

A partir das consideraçóes de Sarmento (2008) verificamos que as crianças possuem papéis sociais importantes. Diante de estudos, como a Sociologia da Infância, Michel Foucault nos alerta para a disciplina e a institucionalização da infância no âmbito da expansão de processos simbólicos, e em específico, de controle social para o pleno exercício do poder que tende a desconsiderar as infâncias em nome de determinadas ordens. A era da modernidade, conforme entendida por Michel Foucault entre os séculos XVIII e XX, nos apresentou diversos procedimentos discursivos e também institucionais sobre a educação além da produção do corpo (ASSIS CÉSAR, 2009). Concordamos que a instituição escolar descrita por Foucault (1987) é um paradigma moderno de disciplinarização do corpo e seus desdobramentos por meio das ações dos sujeitos. Porém, é preciso melhor entender se os corpos permaneceram única e exclusivamente dóceis, já que na perspectiva da infância moderna as crianças são agentes em constantes transformações. Tal viés não é um descrédito da ideia de disciplinarização, segundo Foucault (1987, p. 143): "O exercício da disciplina supóe um dispositivo que obrigue pelo jogo do olhar; um aparelho onde as técnicas que permitem ver induzam a efeitos de poder, e onde, em troca, os meios de coerção tornem claramente visíveis aqueles sobre quem se aplicam."

De acordo com os estudos sociológicos, a infância como categoria social vem se destacando na época moderna, bem como as novas propostas metodológicas no campo da história. A perspectiva de disciplinar os corpos e as mentes, apesar de ainda presente em muitas propostas educacionais, não deve ser algo comum e aceitável. À medida que houve o alargamento das fontes de pesquisas diante da história nova, as produçóes de conhecimentos que versam sobre a infância despontaram.

A produção mais consistente sobre a história da infância toma corpo no interior dos estudos sobre 'novos sujeitos históricos', compreendidos como atores sociais que, 
em suas experiências coletivas, constroem uma história defendida por sua identidade social. Tal perspectiva tornou possível pensar numa história das mulheres, dos operários, dos escravos, etc., o que implicou uma renovação de fontes. (GOUVÊA, 2008, p. 104, grifo do autor).

A nova história foi definida por trazer novos problemas e novos métodos, e sua vinculaçáo com a Antropologia, a Sociologia, a Psicologia e a economia, entre outras, fez surgir novos objetos, a exemplo do corpo e das imagens, entre outros. Essa vinculação com outras áreas também possibilitou focar a história da infância. Aqui abordamos uma nova proposta metodológica, ou seja, a nova vertente historiográfica impulsionada pelas questôes que se revelam, ao invés das respostas que proporcionam. Tudo isso está vinculado à história da educação, ou seja, é chegada a hora de indagar em que medida os novos objetos da nova história coincidem ou não com o objeto da história da educação. Quer dizer: "[...] a história não é senão respostas a nossas indagaçóes, porque não se pode, materialmente, fazer todas as perguntas, descrever todo o porvir, e porque o progresso do questionário histórico se coloca no tempo e é tão lento quanto o progresso de qualquer ciência [...]" (VEYNE, 1998, p. 37). Avaliamos ser possível produzir conhecimentos que se caracterizam por dimensóes ou procedimentos interdisciplinares. Assim, ao tratarmos de aspectos culturais, a educação/instrução rural deve ser enfatizada.

Destronar a história política foi o objetivo número um dos 'Annales' e continua sendo uma preocupação de primeira ordem da história nova, ainda que, como direi adiante, uma nova história política, ou antes uma história de uma nova concepção do fato político, deva tomar seu lugar no domínio da história nova. (LE GOFF, 1995, p. 42, grifo do autor).

Sabemos que muito ainda é preciso fazer e pesquisar sobre a infância. Em nossos estudos elegemos a educação/instrução da infância em áreas rurais das Minas Gerais do início do século XX. Entender a concepção de infância na modernidade, a partir dos dizeres de Buckingham (2000), nos ajuda na melhor compreensão do objeto de pesquisa proposto.

[...] a moderna concepção da infância surgiu como resultado de uma complexa rede de inter-relaçóes entre ideologia, governo, pedagogia e tecnologia, cada uma delas tendendo 
a reforçar as outras. Como resultado, ela desenvolveu-se de formas diferentes e em diferentes níveis, dependendo de cada contexto nacional. (BUCKINGHAM, 2000, p. 59).

Complementando a categoria de infância como resultado de uma complexa rede, Buckingham (2000) apresenta alguns significados da época moderna; diante disso, é possível entender parte dos elementos que permitem repensar questóes pertinentes à infância. As crianças, que até então eram vistas como adultos em miniatura, passaram a constituir uma nova categoria, agora a partir de suas particularidades. A esse respeito podemos até mesmo mencionar as diferenciaçóes no vestuário, crianças que não mais eram vestidas como adultos. Também não negamos que a esse respeito o pertencimento à classe abastada era um facilitador do novo visual, assim as crianças, em determinados contextos, não eram mais vistas como adultos em miniaturas.

Pode-se dizer que a visão de infância como categoria diferenciada surge restrita e em classes mais abastadas - a burguesia. Postman (1999) nos fala sobre a invenção de uma concepção moderna de infância pela qual diz ser a imprensa a responsável; ao mesmo tempo enfatiza que a TV hoje faz com que essa concepçáo seja revista. Ao afirmar isso, o autor dá ênfase ao papel das tecnologias em cada época, na medida em que as tecnologias tanto respondem à demanda dessas diferentes épocas quanto mudam a maneira de os sujeitos se verem, colocando em crise as crenças dessas mesmas épocas.

Buckingham (2000, p. 8) diz que: "A ideia de infância é uma construção social, que assume diferentes formas em diferentes contextos históricos, sociais e culturais." Por isso, o autor em seus estudos menciona infâncias, utiliza o plural como forma de demonstrar as pluralidades existentes sob a questão da infância.

Ao tratarmos de infâncias e não de infância, podemos perceber que, nas consideraçôes de Buckingham (2000), há uma preocupação com os aspectos que também circulam ou que estão presentes muitas vezes no entorno das crianças. A não generalização de uma concepção de infância - constatação contemporânea permite-nos um melhor entendimento de que, dos tempos modernos até nossos dias, o debate em torno de questóes sobre a infância, ou infâncias, se tornou uma necessidade, isso diante das constantes mudanças tecnológicas, tanto as tradicionais quanto as mais recentes.

Quando pensamos no possível entrelaçamento de infâncias com as mídias, no sentido em que as crianças possam ser protagonistas, os significados próprios de seus fazeres e pensares atravessam os diversos contextos, constituindo-se, assim, importantes processos discursivos ou redes de conhecimentos. De acordo com Souza e Salgado (2008, p. 215, grifo do autor). “[...] as crianças também 
constroem valores, determinam quem é 'bom' ou não, o que é válido ou não e o que tem ou náo eficácia, assim como definem quem pode ou não participar de uma cultura lúdica específica." Essa é uma perspectiva de criança ativa, característica de nosso tempo.

A ideia de que a infância é uma construçáo social é hoje um lugar-comum na história e na sociologia da infância e está sendo cada vez mais aceita até mesmo por alguns psicólogos. A premissa central aqui é a de que 'a criança' não é uma categoria natural ou universal, determinada simplesmente pela biologia. Nem é algo que tenha um sentido fixo, em cujo nome se possa tranquilamente fazer reivindicaçóes. Ao contrário, a infância é variável - histórica, cultural e socialmente variável. As crianças são vistas - e veem a sim mesmas - de formas muito diversas em diferentes períodos históricos, em diferentes culturas e em diferentes grupos sociais. Mais que isso: mesmo essas definiçôes não são fixas. O significado de 'infância' está sujeito a um constante processo de luta e negociação, tanto no discurso público (por exemplo, na mídia, na academia ou nas políticas públicas) como nas relaçóes pessoais, entre colegas e familiares. (BUCKINGHAM, 2000, p. 19, grifos do autor).

Ressaltamos que a infância, como categoria social, não se limita aos aspectos biológicos, e não se vincula às definições advindas especificamente das instituiçôes escola e família; é, por assim dizer, um entrelaçamento delas com as diversas redes de bens culturais e/ou simbólicos, que também circulam pelas mídias. Araújo (2007) diz ser necessário distinguir a infância da criança, pois em suas considerações a infância é uma etapa da vida; já o termo criança corresponde ou se refere à pessoa que está vivendo a infância. $\mathrm{O}$ mesmo autor reforça que, no decorrer da modernidade, existem diversas concepçóes de infância. Atualmente a infância e a criança tornaram-se objeto de preocupaçóes educativas.

A construçáo de um conceito de infância pauta-se prioritariamente na diferenciação frente ao mundo do adulto e está ligada à tomada de consciência, por parte do adulto, dessa diferenciação. Essa construção deu-se de maneira articulada a toda uma conjuntura que esboçou a chamada época moderna bom como o surgimento e a consolidação dos modos de produçáo capitalista [...] (PEREIRA, 2002, p. 154). 
Percebemos que a infância moderna é um campo, longe da perspectiva molar dita por Deleuze e Guattari (1995). Ela agrega particularidades em suas diversas redes, assim a história da infância nos revela uma arqueologia outra, bem diversa de uma unicidade. Barros (2008) diz sobre a infância movente, ou seja, no lugar em uma única baliza destacam-se as redes sociais, um hibridismo de culturas, uma mestiçagem de saberes. Isso representa que: "[...] devir criança não é tornar-se criança no mundo do Modelo e da Cópia, mas é afirmar a diferença-crianceira contra a mesmidade do Ser Sensível (quem arenga as suas diferenças relativas ao Princípio de Identidade Adulta)" (CORAZZA; TADEU, 2003, p. 93). A subjetivação está presente no devir criança, e, nesse caso, tanto a Sociologia da Infância quanto a história da infância podem contribuir para um novo entendimento do ser criança, náo pela sua incompletude, mas por suas subjetividades, por suas peculiaridades.

Não obstante, e ao mesmo tempo, a infância é um outro: aquilo que, sempre além de qualquer tentativa de captura, inquieta a segurança de nossos saberes, questiona o poder de nossas práticas e abre um vazio em que se abisma o edifício bem construído de nossas instituiçóes de acolhimento. Pensar a infância como um outro é, justamente, pensar essa inquietação, esse questionamento e esse vazio. (LARROSA, 1999, p. 184).

As consideraçóes que tecemos até aqui nos remetem a uma infância outra, diversa dos princípios do positivismo, uma infância, ou melhor, infâncias repletas de subjetividades e de capacidades de expressar desejos, sonhos e conhecimentos. Larrosa (1999), no excerto citado, nos diz sobre as inquietaçóes, a infância como um outro, e é nesse sentido que trazemos as marcas/memórias de um tempo outro, um tempo do início da República no Brasil, em específico, da República Velha.

Nosso foco é o meio rural e em particular a educação/instrução de crianças. Mas é preciso lembrar, de acordo com Kuhlmann Júnior e Fernandes (2004), a que serviu a escola para as crianças, pois pairava uma ideia de que era possível separála, até então entendida como redentora de uma sociedade às vezes conceituada como profana. A escola era para muitos a tábua de salvação.

A defesa da instituição escolar como o lugar da criança revestiu-se da ilusão de que a escola seria um meio para afastá-la da sociedade, foco da degeneração moral, de modo que, sob a condução de educadores incorruptíveis, ela fosse educada para uma vida social regida por valores 
opostos aos vigentes. Mas seria impossível isolar em uma redoma as crianças e os seus mestres: a escola revelou-se um lugar de reprodução dos processos sociais e culturais. (KUHLMANN JÚNIOR; FERNANDES, 2004, p. 23).

Diante de uma escola em que os processos sociais e culturais se revelavam gradativamente repetidores da ordem estabelecida é que a infância foi colocada na condição de submissão, de reprodutora das determinações no período por nós pesquisado.

\section{A escola rural no início da república brasileira: as infâncias e seus percalços, alguns bordados...}

O Brasil República está inserido dentro do contexto de alteraçóes mais amplas (exemplo disso refere-se à passagem do modo de produção feudal para o capitalista) e seguiu por pontos comuns em diversos países, entre os quais destacamos os seguintes: concentração da terra nas mãos de poucos proprietários, altas taxas de impostos, implementação da mão de obra livre assalariada, entre outros. Nos aspectos sociais, os Estados da Federação, a partir de 1891, procuravam cumprir com seus deveres constitucionais; assim, havia algumas determinaçóes:

Até então, e nas suas linhas gerais, a escola primária fornece um curso de quatro anos de duração, nas zonas urbanas e de três, na zona rural, com um currículo formado por Leitura, Escrita, Língua Pátria, Aritmética, Geografia e História do Brasil, Noções de Ciências Físicas e Naturais, Instrução Moral, Trabalhos Manuais e Ginástica (diferencia-se da escola primária do Império especialmente por não conter disciplinas como a História Sagrada ou doutrina Cristã). (NAGLE, 1990, p. 269).

De acordo com Nagle (1990), é possível verificarmos a diferenciação entre a escola primária nas zonas urbanas em relação às escolas das zonas rurais, principalmente sobre a duração do curso. O Brasil do início da República era predominantemente rural, ou seja, havia um grande contingente de pessoas morando em áreas rurais. Isso não é novidade, ao recordarmos que a base da economia até então era o modelo agrário. "Duas tendências precisam ser ainda mencionadas a respeito da escola primária e da escola normal: a da nacionalização e a da regionalização e ruralização" (NAGLE, 1999, p. 271, grifos nossos). No primeiro 
aspecto, destacamos a nacionalização, fenômeno recorrente desde 1915, contrário à desnacionalização da infância brasileira, ou seja, muitas escolas estrangeiras foram fechadas, principalmente no Sul do país. Tais medidas são tomadas com vistas na Conferência Interestadual de Ensino Primário, de acordo com Nagle (1999). O segundo aspecto diz respeito à regionalização e se caracteriza por ser um esforço para adaptar os padróes de ensino e de cultura da escola primária e normal às especificidades da vida social. "Nesse sentido não contam tanto, por exemplo, as diferenças que vinham sendo adotadas quanto à escola primária urbana e rural pois, neste caso, propunha-se tão somente diminuir o nível dos conhecimentos a serem ministrados às crianças da zona rural" (NAGLE, 1999, p. 272). A regionalizaçáo proposta inicialmente náo se fez presente para as peculiaridades das crianças no meio rural. Por fim, ressaltamos o esforço para a ruralizaçáo da escola primária e normal no Brasil do primeiro quartel do século XX.

A ideologia do Brasil país essencialmente agrícola - táo difundida nesse período para o combate ao incipiente processo de urbanização e industrialização - começa a influenciar os educadores. [...] Aparecem daí as primeiras tentativas de ruralização da escala primária e normal, significando a contribuição destas na tarefa de formar a mentalidade de acordo com a ideologia do Brasil, país essencialmente agrícola. $\mathrm{O}$ passo foi pequeno para chegar à pregação de que a escola deve constituir um instrumento de fixaçấo do homem no campo. (NAGLE, 1999, p. 272-273).

Aqui fica-nos a questão proposta por Sérgio Buarque de Holanda, em sua análise sobre o advento da república: "Como esperar transformaçóes sociais profundas em país onde eram mantidos os fundamentos tradicionais da situação que se pretendia ultrapassar?” (HOLANDA, 1956, p. 96). Em um Brasil moderno e republicano percebemos em seus aspectos sociais permanências do período anterior (Império). Nesse sentido, constatamos que a infância vista a partir das ações por uma educação primária e/ou normal se atrelava ao modelo único de ser humano a ser completado. $\mathrm{O}$ modelo de educação adotado pelos republicanos muito se aproxima do que Foucault (1987) conceituou panoptismo, ou seja, uma educação disciplinadora, preocupada em atender os anseios ideológicos das classes dominantes. A história é repleta de teias e tramas. Segundo Veyne (1998, p. 42, grifos do autor): "A palavra trama tem a vantagem de lembrar que o objeto de estudo do historiador é tão humano quanto um drama ou um romance, Guerra e paz ou Antônio e Cleópatra. Essa trama não se organiza necessariamente, em uma sequência cronológica $[. .]$. 
As escolas localizadas no meio rural serviam também de apoio para os politiqueiros e muitas de suas açóes visavam exclusivamente angariar votos. Lima (2004) nos demonstra a pompa armada em tal locus para dar visibilidade ao poder político.

Nas escolas localizadas na zona rural, ainda que não contassem com a presença maciça de todas as autoridades locais, as festas escolares também serviam ao poder público municipal como fonte de propaganda política. Sendo a escola primária rural o locus principal de atuaçáo do município no âmbito da educaçáo, era para as fazendas que os políticos direcionavam a divulgação dos investimentos em educação e era para lá também que eles se dirigiam em busca de seus eleitores na época da inauguração dos prédios escolares. (LIMA, 2004, p. 147).

É possível inferirmos que a precariedade das escolas no meio rural era algo intencional, na medida em que todo e qualquer investimento do poder público objetivava a troca de votos. Com isso, as escolas primárias se tornaram foco de barganha e/ou controle político em grande parte das terras de Minas Gerais; dessa forma, estabelecia-se um jogo/relação entre política e educação na Primeira República.

Seguem algumas Mensagens ${ }^{4}$ de Presidentes de Minas Gerais, nas quais encontramos alguns indícios sobre o ensino em Minas Gerais. Trazemos o primeiro recorte dos escritos deixados pelo Presidente Francisco Antônio de Salles em Mensagem proferida ao Congresso Mineiro, no ano de 1906. Nesse comunicado oficial, o Presidente afirma que o ensino primário é merecedor de atenção por parte do poder público, e isso nos remete aos dizeres de Nagle (1999), ao mencionar que tal ensino é decisivo na formação da sociedade. Porém, indagamos: sobre qual sociedade se diz? Sobre quais pressupostos assentava a necessidade de formação da sociedade? Quais os recursos orçamentários disponíveis e os necessários para a implementação das medidas remodeladoras? Essas e outras questóes não serão respondidas nesse momento, mas nos trazem lembranças da recente históriaproblema, da história nova em contraposição à história positivista.

Ainda sobre a Mensagem, o Presidente fala da necessidade de os problemas do ensino primário serem enfrentados em duas frentes: uma é a formação de

4 As Mensagens Presidenciais estão disponibilizadas no site da Center for Research Libraries Global Resources Network no seguinte endereço: <http://www.crl.edu/>. 
professores, e tudo indica que, nesse aspecto, o ensino voltado para a técnica era mais urgente, uma vez que o Brasil passava por alteraçóes recentes em relaçáo à adoção da mão de obra livre à escrava. Dessa forma, eram necessários investimentos para qualificar os trabalhadores que se dedicavam ao meio rural. Outro ponto indicado na Mensagem é sobre a criação ou fundação de escolas. Assim, de acordo com o Presidente Francisco Antônio de Salles, essa era uma urgência para a transformação do Brasil. Ressaltamos que, diante do predomínio ou contingente da populaçáo rural, as escolas destinavam-se a formar corpos dóceis, reportando-nos a Foucault (1987). Lembramos, ainda, que, em 1906, ocorreu a reforma do ensino denominada Reforma Joáo Pinheiro. O documento a seguir reforça a necessidade de reformar o ensino.

Como já tive opportunidade de dizer-vos, e ainda confirmo neste momento, o ensino publico primário é o serviço que na actualidade mais atenção e até mesmo sacrificio merece dos altos poderes do Estado, pelo influxo directo e decisivo que exerce na formação da sociedade. Elle exige medidas remodeladoras, que só dependem de recursos orçamentários para serem adoptadas. Já em 1903, referindo-me a assumpto de tanta magnitude, ponderei que o problema do ensino primario precisa ser encarado pelas duas faces - formação do professorado e fundação da escola, cada qual subordinado a um plano traçado systematicamente, para ser executado de modo gradativo, de maneira a poder-se ter a segurança de que, dentro de certo periodo de tempo, esteja operada a sua transformação. (MENSAGEM, 1906, p. 50- 51).

Já no excerto da Mensagem a seguir, que é do Presidente de Minas Gerais Delfim Moreira da Costa Ribeiro, de 1917, é possível percebermos o quanto é enfatizado o ensino público primário, porém, dessa vez, acrescenta-se o ensino elementar profissional. Mais uma vez, encontramos reclames da falta de recursos financeiros necessários para tais investimentos, e, além disso, surge um novo ingrediente, que é a extensão territorial. Parece-nos importante relembrar que a grande extensão territorial não é justificativa para os parcos investimentos na educação rural, visto que essa é uma falha na própria administração pública sobre as inconsistências sociais, além de apontar para as prioridades do governante. Outro fator também apontado na Mensagem é a falta de vias de comunicação; assim, é perceptível que o Estado fez acusaçóes contra si, ou seja, se não havia vias de comunicação é porque o governo também falhava nesse setor; deste modo haviam adversidades que perduravam por mais de uma década para a consolidação da escola pública. 
O ensino publico primario e o elementar profissional vão tendo no nosso Estado acalentador desenvolvimento. Estão, é verdade, sujeitos aos prejudiciaes, porém removíveis, affeitos do meio, á lendidão imposta, e, principalmente, ás difficuladades oriundas das grande extensão territorial e da falta de vias de comunicaçóes. Estes empecilhos vão difficultando a sua mais intensa propagação. Não ha, porém, como contestar que, em Minas, o ensino primario e o profissional elementar, normalizam-se, systematizamse de anno para anno, nas escolas singulares, nos grupos escolares e nos varios institutos disseminados pelas diversas regióes. (MENSAGEM, 1917, p. 27).

Observamos que, na Mensagem acima, há uma forte tendência em não questionar ou contestar as falhas. Assim destaca-se que Minas Gerais estava despontando no ensino primário, mas tal indício deve ser relativizado por dois motivos: o primeiro é pelo nascente movimento reformista, em segundo lugar é por ser uma Mensagem oficial que normalmente vangloria as açóes dos próprios governantes.

As transformaçóes da escola primária, na década dos anos vinte, se processam principalmente em consequência do movimento reformista e remodelador da escola normal que então se desenvolve. Tal movimento vai dar à escola normal uma nova feição. O que se observa, agora, é uma ampliaçáo da duraçáo do curso bem como um encaminhamento para o equilíbrio entre as matérias de formaçáo geral e as de habilitação profissional. (NAGLE, 1999, p. 271).

Ao longo da Primeira República verificamos que as açóes sobre ou para a escola primária não relevaram a categoria de infância na perspectiva moderna anteriormente abordada, pelo menos isso é o que constatamos por meio dos documentos analisados; assim, nesse período, destacou-se a singularidade 5 do ser criança, suas falhas ou suas possíveis incompletudes. A educação é entendida por ser um dos pilares da edificação da sociedade civilizada, porém a infância é descartada em suas características sociais.

5 O que chamamos de singularidade se relaciona a um modo específico de ver e entender a criança, porém Gouvêa (2003, p. 201), diz sobre a "pluralidade, ou seja, as infâncias, ao mencionar questóes éticas, sociais e de gênero". 


\section{Foto 1 - Grupo de crianças em área rural}

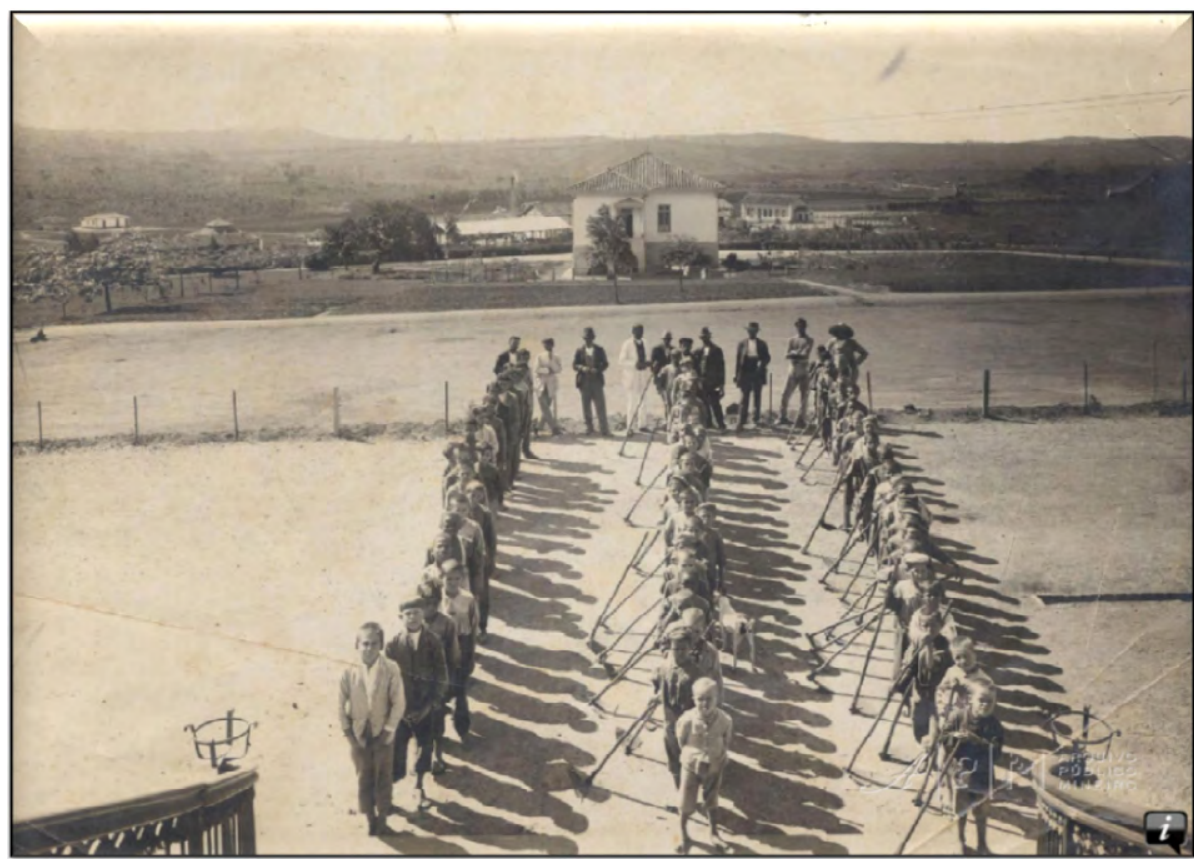

Fonte: Arquivo Público Mineiro. Disponível em: <http://www.siaapm.cultura.mg.gov.br/>. [20-]

A fotografia então mostrada (Foto 1), embora não tenha data, nos serve como fonte de pesquisa, pois ela explicita parte do contexto infantil rural. Apesar da falta de dados mais precisos sobre esse registro inferimos que em tal área havia uma escola primária rural, isso por dois motivos: o primeiro é pelo contingente de crianças (meninos) reunidas no mesmo local; já o segundo é pelo direcionamento das propostas educativas que, em determinado momento, enfatizavam o ensino técnico. Avaliamos que os instrumentos de trabalho (enxadas) dispostos pelas crianças reforçam a necessidade de preparar mão de obra para o meio rural. Dessa forma, a escola tinha um papel fundamental, ou seja, preparar os corpos dóceis para servirem ao sistema capitalista da Primeira República. Ao fundo, é possível observarmos os olhares atentos dos adultos. Talvez entre eles existissem alguns professores e/ou instrutores das práticas agrícolas e/ou educação/instrução primária. 


\section{Foto 2 - Crianças em trabalho rural}

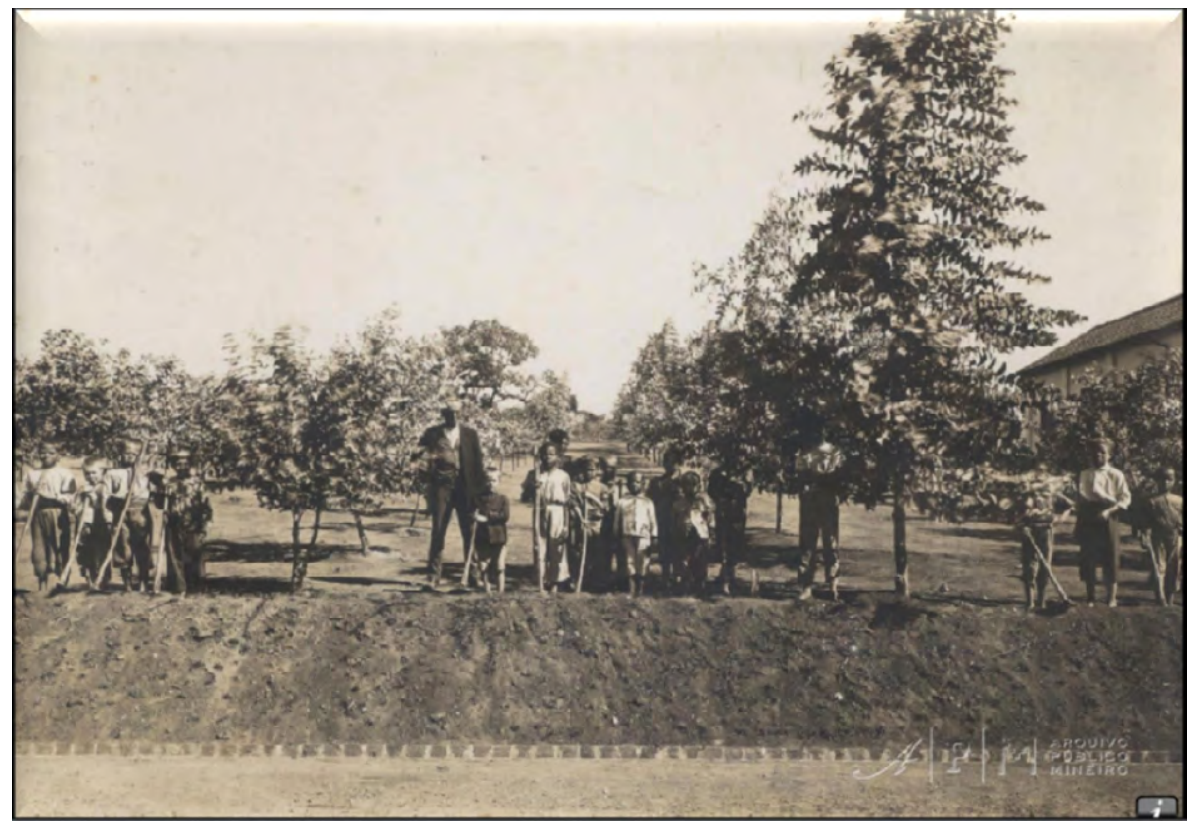

Fonte: Arquivo Público Mineiro. Disponível em: <http://www.siaapm.cultura.mg.gov.br/>. [20--]

A fotografia mostrada (Foto 2) também nos demonstra parte do contexto das crianças no período republicano ${ }^{6}$. Tais crianças estáo dispostas com as ferramentas utilizadas nas lavouras, e talvez essa seja uma plantação de café em alguma localidade de Minas Gerais. Trazemos essa foto para externar a representação da criança no mundo do trabalho, parte integrante da geração de riquezas, mas em nenhum momento considerada em suas peculiaridades. Acreditamos que educação/instrução primária, embora não estabelecesse vínculos mais explícitos com o mundo do trabalho, assegurava uma tendência de defesa da infância apenas como extensáo do adulto. Nesse sentido, o trabalho na lavoura era mais uma vez justificado para garantir o desenvolvimento do sistema capitalista.

Em Mensagem ao congresso mineiro em 1907, o Presidente Dr. João Pinheiro da Silva diz sobre a necessidade de o ensino primário vincular-se às atividades agrícolas. Dessa forma, entendemos que a Foto 2 tende a nos demonstrar parte do universo das crianças que viviam no meio rural no início da século $\mathrm{XX}$, ou seja,

6 Acreditamos que a fotografia represente parte do contexto das crianças na Primeira República. No processo de coleta de dados náo foi possível identificar a sua localidade e datação. 
um contexto marcado por diversos problemas, conforme asseverou Barros (2013). "Avulta depois, como necessidade tambem urgente, após a do ensino das creanças, a do ensino primario da agricultura aos adultos, habituando-os ao manejo simples das aperfeiçoadas machinas agrícolas" (MENSAGEM,1907, p. 6).

A partir de meados do século XIX, a educação foi necessária para fundar uma sociedade harmônica, e talvez esse processo tenha culminado na universalizaçáo do ensino. Mesmo assim, as camadas dirigentes (elites) pensaram e consolidaram uma escola para os pobres, mas sobretudo assegurando a mão de obra necessária para o desenvolvimento do país. "A supressão da infância não é temporária. Ela se insere no complicado e perigoso processo de ampliação forçada do chamado exército industrial de reserva, que torna descartável e sem esperança parcelas amplas da humanidade" (MARTINS, 1991, p. 15).

\section{Alguns lampejos das considerações: traçados de um dos bordados...}

\section{Retrato}

Quando menino encompridava rios. Andava devagar e escuro - meio formado em Silêncio. Queria ser a voz em que uma pedra fale. Paisagens vadiavam no seu olho. Seus cantos eram cheios de nascentes. Pregava-se nas coisas quanto aromas. (BARROS, 2004, p. 47).

Percebemos que a ideia de educar as crianças, ao longo da Primeira República, estava atrelada aos novos templos de civilização. De acordo com Souza (1998), assim, a formação ou a deformação pleiteava um ser ordeiro, civilizado e, sobretudo, obediente. Das escolas isoladas, de uma só turma às escolas reunidas e, por fim, aos grupos escolares, a reforma de 1906 trazia em seu bojo profundas transformaçóes para organizar as escolas. Entre tais alterações, destacamos a construção de espaços próprios para a educação escolar. "Essa reforma cria as condiçôes para a constituição e afirmação de uma nova cultura escolar em Minas Gerais, e sua capital, Belo Horizonte, tornou-se o centro irradiador desse movimento" (VAGO, 2007, p. 284). A escola, por um lado, carregava a responsabilidade para moldar as crianças, impondo-lhes hábitos culturais, e, por outro lado, prepará-las para o mundo do labor. 
Aqui destacamos novamente a proposição da ideia de criança incompleta e selvagem, já que civilizar como foco da salvação dos corpos era a bola da vez. Nessa perspectiva, talvez estivesse sendo implementada uma pedagogia da boa forma. A escola foi, sem dúvida, de acordo com Foucault (1987), o locus privilegiado das diversas puniçốes.

A educação/instrução primária foi indispensável para a consolidação do regime republicano. Já em 1906 ela teve como objetivo trazer novas configuraçóes, ou seja, dos pardieiros aos palácios, conforme cita Faria Filho (2000). Assim, a educação ganha importância para o desenvolvimento do projeto prometeico da nação brasileira, diante das consideraçóes de Souza (1998).

Nesse contexto, as representaçóes de infância no singular ficaram restritas aos possíveis aproveitamentos da criança no mundo do trabalho tão comum aos adultos. Nesse período, as escolas rurais eram consideradas atrasadas e náo merecedoras de investimentos diversos. Tanto nas Mensagens dos Presidentes quanto nas fotografias encontramos representaçóes de uma escola pública marcada pela precariedade.

As Mensagens dos Presidentes tinham diversos objetivos, entre eles destacamos dois: o primeiro era informar a sociedade o que tange à educaçáo, ou seja, dar visibilidade para as açóes dos governantes; o segundo era esclarecer sobre a prestação de contas referente aos investimentos públicos de responsabilidade dos agentes políticos no exercício de seu ofício. Pensamos que a escola era o elo de ligação entre o povo e o poder executivo/legislativo.

Por fim, a oferta de ensino agrícola técnico para crianças era uma forma de fixar a população no meio rural e estabelecer vínculos entre o morar e o trabalho, porém, sem levar em consideração as especificidades das infâncias.

\section{Referências}

ARAÚJO, José Carlos Souza. Marcos filosóficos da modernidade em torno da educação da criança: antropologias da infância em disputa? In: ARAUJO, José Carlos Souza; CARVALHO, Carlos Henrique de; MOURA, Esmeralda B. Blanco de. (Org.). A infância na modernidade: entre a educação e o trabalho. Uberlândia: EDUFU, 2007.

ARIÈS, Philippe. História social da criança e da família. 2. ed. Rio de Janeiro: LTC, 2006.

ASSIS CÉSAR, Maria Rita de. (Des)educando corpos: volumes, comidas, desejos e a nova pedagogia alimentar. In: RAGO, Margareth; VEIGA-NETO, Alfredo (Org.). Para uma vida não fascista. Belo Horizonte: Autêntica, 2009. 
BARROS, Josemir Almeida. Rádio e educaçáo: de ouvintes a falantes, processos midiáticos com crianças. 2008. 152 f. Dissertação (Mestrado em Educação) - Faculdade de Educação, Universidade do Estado do Rio de Janeiro, Rio de Janeiro, 2008.

BARROS, Josemir Almeida. Organização do ensino rural em Minas Gerais, suas muitas faces em fins do XIX e início do XX (1899 - 1911). $349 \mathrm{f}$. (Doutorado em Educação) - Faculdade de Educação, Universidade Federal de Uberlândia, Uberlândia. 2013. Disponível em: <http://www.bdtd.ufu.br/tde_ busca/>.

BARROS, Manoel de. Concerto a céu aberto para solos de ave. 4. ed. Rio de Janeiro: Record, 2004.

BOIS, Guy. Marxismo e história nova. In: LE GOFF, Jacques. A história nova. 3. ed. São Paulo: Martins Fontes, 1995. p. 241-260.

BUCKINGHAM, David. Crescer na era das mídias eletrônicas. São Paulo: Loyola, 2000.

CERTEAU, Michel de. A escrita da história. 2. ed. Rio de Janeiro: Forense Universitária, 2006.

CORAZZA, Sandra; TADEU, Tomaz. Composiçóes. Belo Horizonte: Autêntica, 2003.

DELEUZE, Gilles; GUATTARI, Félix. Mil platôs: capitalismo e esquizofrenia. São Paulo: Editora 34, 1995. v. 1.

FARIA FILHO, Luciano Mendes de. Dos pardieiros aos palácios: cultura escolar e urbana em Belo Horizonte na Primeira República. Passo Fundo: Universidade Passo Fundo, 2000.

FOUCAULT, Michel. Vigiar e punir. 26. ed. Petrópolis: Vozes, 1987.

GOUVÊA, Maria Cristina Soares de. A escrita da história da infância: periodização e fontes. In: SARMENTO, Manuel Jacinto; GOUVÊA, Maria Cristina Soares de. (Org.). Estudos da infância: educaçâo e práticas sociais. Petrópolis: Vozes, 2008. p. 97-118.

GOUVÊA, Maria Cristina Soares de. A escolarização da "meninice" nas Minas oiticentistas: a individualização do aluno. In. VEIGA, Cynthia Greive; FONSECA, Thais Nívia de Lima (Org.). História e historiografia da educaçáo no Brasil. Belo Horizonte: Autêntica, 2003. 
HOLANDA, Sérgio Buarque de. Raízes do Brasil. 3. ed. Rio de Janeiro: J. Olympio, 1956.

KUHLMANN JUNIOR, Moysés Jr.; FERNANDES, Rogério. Sobre a história da infância. In: FARIA FILHO, Luciano Mendes de. A infância e sua educaçáo: materiais, práticas e representaçóes. Belo Horizonte: Autêntica, 2004. p. 15-34.

LARROSA, Jorge. Pedagogia profana: danças, piruetas e mascaradas. Belo Horizonte: Autêntica, 1999.

LE GOFF, Jacques. A história nova. 3. ed. São Paulo: Martins Fontes, 1995.

LIMA, Sandra Cristina Fagundes de. Memória de si, história dos outros: Jerônimo Arantes, educação, história e política em Uberlândia nos anos de 1919 a 1961. 2004. 401 f. (Doutorado em História) - Faculdade de História, Universidade Estadual de Campinas, Campinas, 2004.

MARTINS, José de Souza. O massacre dos inocentes: a criança sem infância no Brasil. São Paulo: Hucitec, 1991.

MENSAGEM dirigida pelo Presidente do Estado Francisco Antônio de Salles ao Congresso Mineiro em sua $4^{\mathrm{a}}$. Sessão da $4^{\mathrm{a}}$. Legislatura no anno de 1906 . Bello Horizonte: Imprensa official do Estado de Minas Geraes, 1906. Disponível em: <http://www.crl.edu/brazil/provincial/minas_gerais>. Acesso em: 14 fev. 2017.

MENSAGEM dirigida pelo Presidente do Estado Dr. João Pinheiro da Silva ao Congresso Mineiro em sua $1^{a}$. Sessão da 5a. Legislatura no anno de 1907. Bello Horizonte: Imprensa official do Estado de Minas Geraes, 1907. Disponível em: <http://www.crl.edu/brazil/provincial/minas_gerais>. Acesso em: 14 fev. 2017.

MENSAGEM dirigida pelo Presidente do Estado Dr. Delfim Moreira da Costa Ribeiro ao Congresso Mineiro em sua 8a. Sessão ordinária da 7a . Legislatura no anno de 1917. Bello Horizonte: Imprensa official do Estado de Minas Geraes, 1917. Disponível em: $<$ http://www.crl.edu/brazil/provincial/minas_gerais>. Acesso em: 14 fev. 2017.

NAGLE, Jorge. A educação na Primeira República. In: HOLANDA, Sérgio Buarque de. O Brasil republicano: sociedade e instituiçóes (1889 - 1930). 4. ed. Rio de Janeiro: Bertrand Brasil S.A., 1990. v. 9. p. 259-292.

NAGLE, Jorge. Educação e sociedade na Primeira República. São Paulo: Edusp, 2009.

PEREIRA, Rita Marisa Ribes. Tudo ao mesmo tempo agora: consideraçóes sobre a infância no presente. In: GONDRA, José. (Org.). História, infância e escolarizaçáo. Rio de Janeiro: 7Letras, 2002. 
POSTMAN, Neil. O desaparecimento da infância. Rio de Janeiro: Graphia, 1999.

QVORTRUP, Jens. Childhood in Europe: a New Fiel of Social Research. In: CHISHOLM, L. et al. (Org.). Growing Up in Europe - Contemporany Horizons in Childhood and Youtl Studies. Berlim/Nova York: Walter de Gruyter, 1995. p. 7-21.

SARMENTO, Manuel Jacinto. Sociologia da infância: correntes e confluências. In: SARMENTO, Manuel Jacinto; GOUVÊA, Maria Cristina Soares de. (Org.). Estudos da infância: educação e práticas sociais. Petrópolis: Vozes, 2008. p. 17-39.

SOUZA, Rosa Fátima de. Templos de civilizaçáo: a implantação da escola primária graduada no Estado de São Paulo (1890-1910). São Paulo: UNESP, 1998.

SOUZA, Solange Jobim; SALGADO, Raquel Gonçalves. A criança na idade mídia: reflexóes sobre cultura lúdica, capitalismo e educação. In. SARMENTO, Manuel Jacinto; GOUVÊA, Maria Cristina Soares de. (Org.). Estudos da infância: educação e práticas sociais. Petrópolis: Vozes, 2008 p. 207-221.

VAGO, Tarcísio Mauro. "Uma verdadeira revolução de costumes": educaçáo de corpos infantis na reforma de ensino de 1906 em Minas Gerais. In: LOPES, Alberto; FARIA, Luciano Mendes Filho; FERNANDES, Rogério (Org.). Para a compreensão histórica da infância. Belo Horizonte: Autêntica, 2007. p. 283-302. VEYNE. Paul. Como se escreve a história: Foucault revoluciona a história. 4. ed. Brasília, DF: UNB, 1998. 